Review

\title{
Quantitative Modeling of Human Responses to Changes in Water Resources Availability: A Review of Methods and Theories
}

\author{
Karen S. Meijer *, Femke Schasfoort and Maike Bennema
}

check for

updates

Citation: Meijer, K.S.; Schasfoort, F.; Bennema, M. Quantitative Modeling of Human Responses to Changes in Water Resources Availability: A Review of Methods and Theories. Sustainability 2021, 13, 8675. https:// doi.org/10.3390/su13158675

Academic Editors: Philippe

J. Giabbanelli and

Arika Ligmann-Zielinska

Received: 15 June 2021

Accepted: 29 July 2021

Published: 3 August 2021

Publisher's Note: MDPI stays neutral with regard to jurisdictional claims in published maps and institutional affiliations.

Copyright: (c) 2021 by the authors. Licensee MDPI, Basel, Switzerland. This article is an open access article distributed under the terms and conditions of the Creative Commons Attribution (CC BY) license (https:// creativecommons.org/licenses/by/ $4.0 /)$.
Deltares, Boussinesqweg 1, 2629 HV Delft, The Netherlands; femke.schasfoort@deltares.nl (F.S.); maike.bennema@deltares.nl (M.B.)

* Correspondence: karen.meijer@deltares.nl

\begin{abstract}
In rural areas in developing countries where livelihoods directly depend on agriculture, shortage of water can have severe socio-economic and humanitarian consequences and has been suggested to result in conflict and migration. Understanding such responses is important for the development of effective water management policies and other interventions. However, despite the availability of extensive knowledge on water-related human behavior, water resources planning studies do not always look beyond direct impacts. Therefore, this paper assesses literature on water-related human responses, the quantification and conceptualization methods and theories used, the scale at which models are applied, and the extent to which findings are used to make policy recommendations. We found system dynamics approaches mostly applied for policy evaluations, but often with a limited integration of human behavior beyond water use; agent-based models seem to be suited for policy analysis, but only limitedly applied for that purpose; and statistical studies to present the widest range of human responses and explanatory factors, but without making the behavioral mechanisms explicit. In fact, only a limited number of studies was based on behavioral theories. Based on these findings we recommend eight steps to facilitate quantification of human responses for water resources planning purposes.
\end{abstract}

Keywords: human responses; quantitative modeling; water resources planning; water availability; water shortage; drought

\section{Introduction}

Understanding human responses to changes in water availability is important to develop effective water management and climate adaptation strategies. Water is of key importance for the lives and livelihoods of people, particularly in rural areas. Therefore, changes in water availability, either through climate change or man-made, can lead to a loss of income from agriculture or from other water-related ecosystem services, such as pastures for cattle or fish production in lakes. Such changes have been related to famine and impoverishment [1], to displacement and migration [2], and to social tensions and conflict [3]. However, such impacts are not always straightforward, since people make individual decisions to adapt their livelihoods [4], to stay or to move away [5,6], to cooperate or to fight. Various factors play a role in such decisions, such as (1) the motivation and ability to adapt [4], (2) resources and social networks that facilitate migration [7], (3) perceptions of inequality [8] or (4) the need to defend one's own interest in the absence of a functioning government [9]. Such autonomous decisions may also cause a feedback on the water system. Di Baldassarre et al. [10] listed various counterintuitive consequences of water and climate-related policies that result from unexpected behavior of people in response to these policies; for example, continued water shortage after improvements in water supply as a result of more intensive water use practices, or an increase in flood risk as a result of intensified land use after levee construction. This indicates that the dynamics of 
human-water systems are a large source of uncertainty in policy making. Not taking such dynamics into account in planning water resources management or climate adaptation strategies could lead to policies that are either ineffective or have unintended negative social impacts.

To facilitate the consideration of human responses in water resources planning and climate adaptation, it would be useful to assess the impact on different societal groups under various future projections of, amongst others, climate change or as a result of certain water management measures [11,12]. Planning of water resources management and climate adaptation often involves quantitative modeling to address the interlinkages between water availability, water demand, and water regulation throughout the basin and over time [13]. Integrating human responses in such quantitative modeling exercises is thus one of the ways to quantify the impact of interventions while considering the dynamics in human-water systems.

Over the past years the attention for social impacts from changes in water management systems has increased. This ranges from assessing socio-economic/sectoral impacts of water resources management in Integrated Water Resources Management [14-16], to understanding the interactions between water and human systems in the field of sociohydrology [17]. Konar et al. [18] divided the existing socio-hydrology research into four groups: (1) water metabolism-the economic use of water; (2) interactions between humans and droughts, (3) interactions between humans and floods and (4) the role of human institutions, policy and management. The focus of the socio-hydrology research is on the two-way interactions between water and humans. This therefore mainly addresses how, as a result of changes in water systems, humans have altered their behavior regarding water use and management which in turn affects the water system and humans through feedback loops. The socio-hydrology research pays less attention to other societal dynamics that can be triggered by changes in water availability, although some examples are found in studies addressing migration [19] and suicide among farmers as a result of reduced irrigation water [20]. However, it seems that no systematic attention has been paid to how the impacts of water on people lead to other types of responses, that could result in the societal and humanitarian impacts mentioned above, and that no concepts of these types of human responses and societal consequences have been developed in the field of hydrology and water management.

Therefore, in this paper we carried out a literature review to assess what methods, theories or concepts authors have used to quantify human responses to changes in water availability, with the aim of drawing lessons and identifying generic approaches or theories that can guide assessment of human responses to drought and water scarcity to inform water resources planning.

\section{Materials and Methods}

\subsection{Study Identification and Selection}

To answer our research question, we conducted a structured literature assessment of the ways in which human responses to changes in water resources availability are quantified. We used Scopus [21] to search for relevant articles that quantify human responses to changes in water resources availability. The search included all available scientific journal articles in the English language until May 2019, within subject areas relevant to the environment (environment, agriculture, earth sciences), modeling (engineering, mathematics, computation sciences, and human behavior (social sciences, multi-disciplinary research, arts, economy, decision-making and psychology). We ran two searches, the first focused on the combination of water availability and human responses (response related search in Table 1), and the second focused on the combination of water availability and specific model types frequently used to model human behavior (model related search in Table 1). In the search functions we included the various common alternatives for each of our three key words: quantification; human responses, changes in water resources. In addition to quantification, we also searched for terms related to modeling and simulation. 
We considered four types of human responses: (1) not responding, which may result in increased poverty, (2) livelihood adaptation, legally or illegally, (3) human mobility either referred to as refugees, internal displacement or migration, and (4) protest, social unrests and violent conflicts. In addition to the fact that many households will employ a variety of coping strategies, there is also some overlap between categories. For example, migration is a way of livelihood adaptation, as it will enable the migrant to engage in a different type of income strategy in another area. Violent behavior can be a way to illegally appropriate resources, and can be considered an undesirable way of obtaining alternative income or sustenance. Violent behavior can be a reaction to the inability to adapt to a reduction in water resources availability but can also be a way to diversify income. To understand the further societal impacts of changes in water availability, we considered it useful to address these types of consequences explicitly, while being aware of their different character. Figure 1 displays the numbers of studies that were identified, screened, and included. From the 759 unique studies identified through the search, 39 studies where identified that dealt with the quantification of human responses in relation to changes in water availability.

Table 1. Search functions used in Scopus to search in titles, abstracts, and keywords. (The wildcard * is included in combination with truncated words to search for multiple forms of the same word or to allow for different spellings).

\begin{tabular}{|c|c|}
\hline Search Topic & Search Function \\
\hline Response related & $\begin{array}{l}\text { ("water shortage" OR "water scarcity" OR "water stress" OR "water } \\
\text { demand" OR "water availability" OR drought *) AND ("response *" } \\
\text { OR "behavior * } \mathrm{r}^{*} \text { ) AND (model * OR quantif * OR simulat*) AND } \\
\text { (conflict * OR migra * OR displace * OR refuge * OR livelihood * OR } \\
\text { poverty) }\end{array}$ \\
\hline Model type related & $\begin{array}{c}\text { ("water shortage" OR "water scarcity" OR "water stress" OR "water } \\
\text { demand" OR "water availability" OR drought *) AND ("system } \\
\text { dynamic *" OR agent-based OR "behavio*r* model *" OR } \\
\text { "discrete-event") }\end{array}$ \\
\hline
\end{tabular}

\subsection{Study Assessment}

We systematically analyzed all studies by assessing five aspects: (1) the types of human responses that are considered, (2) the types of quantification methods used, (3) the theory or other method used to conceptualize the relationship between water and the human responses, (4) the geographical scale at which the analysis was conducted, and (5) the ways the results were linked to policy recommendations. We did not use fixed categories upfront. Instead, we made an inventory of the ways these five aspects were addressed or applied in the study, and subsequently grouped them in sub-categories for further analysis. Short definitions of each of the five aspects are included in Table 2. 


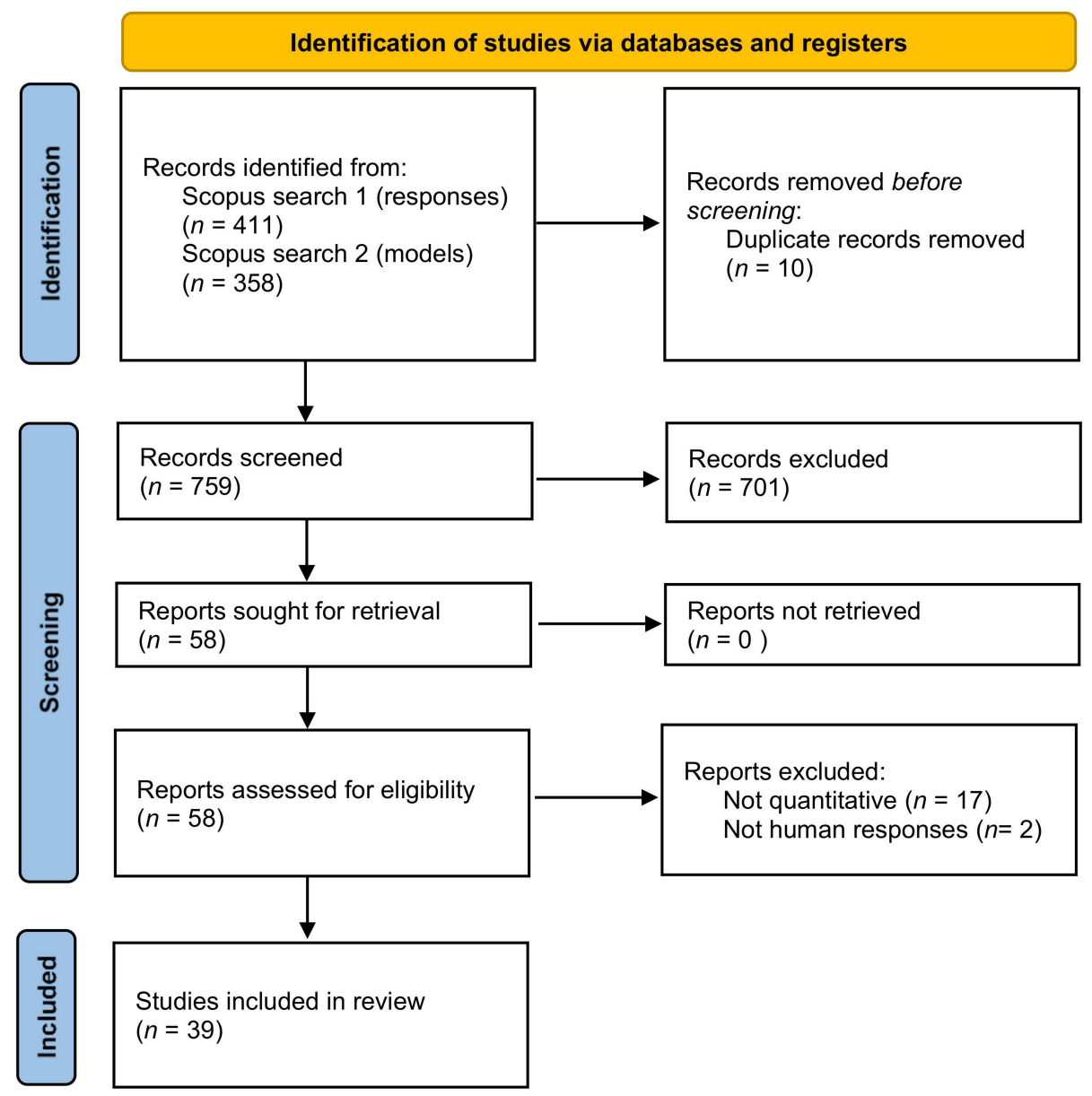

Figure 1. Numbers of studies identified, screened, and included following the PRISMA 2020 flow diagram.

Table 2. Categories and sub-categories for analysis of the studies.

\begin{tabular}{|c|c|}
\hline Aspect & Definition \\
\hline Quantification approach & $\begin{array}{l}\text { Types of models or quantification method to } \\
\text { quantitatively assess human behavior in response to } \\
\text { changes in water availability }\end{array}$ \\
\hline Human responses & $\begin{array}{l}\text { All human actions in responses to a change in water } \\
\text { resources or water-related ecosystem services }\end{array}$ \\
\hline $\begin{array}{l}\text { Theories and approaches to } \\
\text { conceptualizing human responses to } \\
\text { changes in water availability }\end{array}$ & $\begin{array}{c}\text { Theories applied to conceptualize human behavior, } \\
\text { or indication of other approaches not explicitly } \\
\text { based on an existing theory }\end{array}$ \\
\hline Policy application & $\begin{array}{c}\text { Extent to which analysis is used to derive policy } \\
\text { measures or policy recommendations }\end{array}$ \\
\hline Geographical scale & The spatial unit at which the analysis was conducted \\
\hline
\end{tabular}

\section{Results}

3.1. Characterization of the Studies Selected: Communities, Geographical Scales and Quantification Methods

The 39 papers have a strong focus on rural populations, especially on farmers and herders. This may result from the fact that there is a strong link between water availability and rural livelihoods, with $70 \%$ of global freshwater used for agriculture, and agriculture being important as a livelihood basis for rural communities (See Table 3). This is particularly the case in Africa and Asia, which shows clearly from the geographical spreading of the studies (See Figure 2). 
Table 3. Characterization of selected studies.

\begin{tabular}{|c|c|c|c|}
\hline Study & Communities & Location and Scale & Method \\
\hline Alam, 2015 & Farmers & Rasjahi district, Bangladesh & statistical \\
\hline Ashraf et al., 2014 & Farmers & Balochistan province, Pakistan & statistical \\
\hline Asseng et al., 2010 & Farmers & Katanning region, Australia & agent-based \\
\hline Bai et al., 2019 & Livestock herders & $\begin{array}{l}\text { Hulun Buir/Inner Mongolia, } \\
\text { China }\end{array}$ & statistical \\
\hline Berger, et al., 2017 & Farmers & National level, Ethiopia & agent-based \\
\hline Berhanu and Beyene, 2015 & Livestock herders & Southern Ethiopia & statistical \\
\hline Bommel et al., 2014 & Farmers & Sub-national level, Uruguay & agent-based \\
\hline Boone et al., 2011 & Livestock herders & Kajiado District, Kenya & agent-based \\
\hline Bradley and Grainger, 2004 & Farmers and livestock herders & Silvo-pastoral zone of Senegal & other \\
\hline Butler and Gates, 2012 & Livestock herders & North Kenya, South Somalia & optimization \\
\hline Carter and Janzen, 2017 & All households & Stylized case & optimization \\
\hline Clark and Crabtree, 2015 & Livestock herders & mountain-steppe-taiga, Mongolia & agent-based \\
\hline Collman et al., 2016 & All households & National level, Somalia & system dynamics \\
\hline Desta and Coppock, 2004 & Livestock herders & Southern Ethiopia & statistical \\
\hline Dieguez Cameroni et al., 2014 & Livestock herders & Basaltic region of Uruguay & agent-based \\
\hline Entwisle et al., 2008 & All households & Nang Rong District Thailand & agent-based \\
\hline Esquivel-Hernández et al., 2018 & All households & National level, Costa Rica & statistical \\
\hline Fagariba et al., 2018 & Farmers & Upper east region of Ghana & statistical \\
\hline Gies et al., 2014 & Farmers and livestock herders & $\begin{array}{c}\text { Juba river basin, Ethiopia, Kenya } \\
\text { and Somalia }\end{array}$ & system dynamics \\
\hline Giuliani et al., 2016 & Farmers & Adda river basin, Italy & system dynamics \\
\hline Gohari et al., 2017 & Farmers & Zayandeh-Rud River Basin, Iran & system dynamics \\
\hline Gori Maia et al., 2018 & Livestock herders & Sertao, Brasil & statistical \\
\hline Grosskopf et al., 2015 & Livestock herders & National level, Uruguay & agent-based \\
\hline Hailegiorgis et al., 2018 & Rural households & South Omo Zone, Ethiopia & agent-based \\
\hline Hassani-Mahmooei and Parris, 2012 & All households & National level, Bangladesh & agent-based \\
\hline Kansiime and Mastenbroek, 2016 & Farmers & West Nile region, Uganda & statistical \\
\hline Khanian et al., 2019 & All households & Famenin County, Iran & statistical \\
\hline Kotir et al., 2016 & All households & Volta River Basin, Ghana & system dynamics \\
\hline Krömker et al., 2008 & All households & $\begin{array}{c}\text { Andhra Pradesh, India; Algarve } \\
\text { and Alentejo, Portugal; Volgograd } \\
\text { and Saratov, Russia }\end{array}$ & agent-based \\
\hline Lawson and Kasirye, 2013 & All households & National level, Uganda & statistical \\
\hline Martin et al., 2016 & Livestock herders & $\begin{array}{l}\text { High Atlas Mountains, } \\
\text { Morocco }\end{array}$ & agent-based \\
\hline Miller et al., 2014 & Livestock herders & Tarangire National Park, Tanzania & statistical \\
\hline Okpara et al., 2016 & All households & Small Lake Chad basin, Chad & statistical \\
\hline Pérez et al., 2016 & Farmers & Pumpa irrigation system, Nepal & agent-based \\
\hline Pope and Gimblett, 2015 & Farmers & Rio Sonora Watershed, Mexico & agent-based \\
\hline Ryu et al., 2012 & Farmers & Eastern Snake Plain Aquifer, USA & system dynamics \\
\hline Twongyirwe et al., 2019 & Farmers & Isingiro district, Uganda & statistical \\
\hline Warner et al., 2015 & Farmers & $\begin{array}{c}\text { Tempisque River Basin, Costa } \\
\text { Rica }\end{array}$ & statistical \\
\hline Yazdanpanah et al., 2014 & Farmers & Boushehr province, Iran & statistical \\
\hline
\end{tabular}

Most of the modeling of human responses is done at the sub-national scale, on regional, state/province or community level. This makes sense for three reasons: (1) to understand the changes in water systems that can induce human responses it is important to understand how these changes affect specific types of land use, such as deltas or irrigation areas, (2) modeling (groups of) actors of too large areas would result in very large models. Largescale models would therefore require the aggregation of individual actors into actor groups. (3) The detailed data collection through interviews as applied in most studies is resourceintensive and can only be done among a limited set of agents. Nevertheless, it would be interesting to explore how small-scale findings can be applied to larger scales, to further improve continental scale assessments of societal impacts of, for example, climate change. 


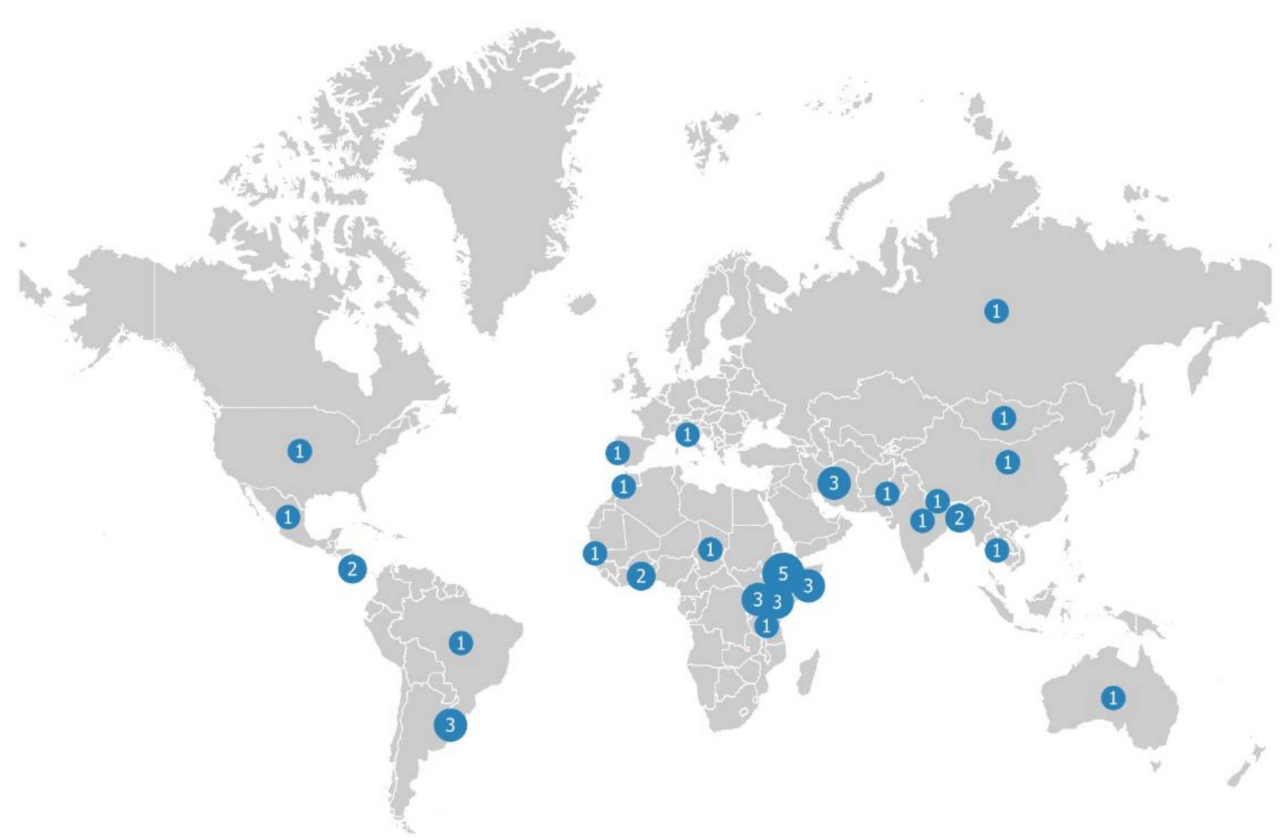

Figure 2. Geographical spread of study areas in selected papers. Dots are placed in the center of the country where the study took place. The numbers indicate the number of papers addressing (an area within) a country, also visualized through larger dot sizes.

Four categories of quantification methods were found, with one paper not fitting any of the categories and assigned the label 'other'. We find that most studies $(n=16)$ use statistical methods (category 1 ) to assess correlations between responses and explanatory factors. Fourteen studies simulated human decisions in response to changes in their environment at the level of individuals or actor groups, mostly agent-based models (category 2). Six studies used system dynamics models (category 3), and two studies used optimization methods (category 4). Quantification by means of models does not however necessarily imply simulation or optimization. For example, [22] developed equations to identify equilibrium situations; whereas [23] quantified thresholds at which pastoralists would switch between survival and performance strategies. This last paper is assigned the category 'other' since it did not fit any of the four categories that we distinguished.

Often system dynamics models and agent-based models are connected to other models that represent the biophysical system, such as hydrological or water allocation models. For example, Gies et al. [24] used a combined hydrological and system dynamics model to assess changes in income and the population affected by migration in relation to a variety of water and land management measures such as water harvesting, water storage or irrigation efficiency. Gohari et al. [25] used a combined hydrological, socio-economic and agricultural system dynamics model to assess the impacts of climate change and various adaptation strategies. Human responses are included as feedback mechanisms in which decisions are made to maximize utility at system level, and in which variations in utility affect water demand.

\subsection{Human Responses}

The selected 39 papers all quantify human responses as a result of changes in water availability (See Table 4 for an overview). We only mention which types of response options were included in the analyses in the various studies. This does not imply that the authors found these responses to be the consequence of changes in water availability. These response options can be grouped into five categories. Short-term coping strategies (category 1), other than alternative income, was mentioned in 13 of the papers, and were found to consist of (1) reducing consumption [26,27], (2) obtaining additional income by selling assets [26-28], borrowing money or products [27,28], or (3) receiving food aid, additional 
remittances and other types of community sharing or external assistance [23,29-31]. In addition, short-term coping could require buying fodder to replace natural vegetation [26,27]. Livelihood adaptation is the most frequently described response, mentioned in 30 papers. Adaptation is achieved through either or both income diversification $(n=10)$ to be less dependent on income sources subject to water availability, and adaptation of agricultural practices $(n=27)$. We considered these as two separate human response categories. Income diversification (category 2) can consist of a (partial) shift to another livelihood, such as combining pastoralism with cereal cultivation or charcoal making $[32,33]$ or finding paid labor on or off the farm [34]. Adaptation within the agricultural sector (category 3 ) is done in various ways, for example, by managing water and other inputs [28,35], improving water supply infrastructure and wells [31,36], by making well-informed choices on crops or crop varieties, livestock management strategies [32,37], and new ways of preparing land or planting crops $[31,38,39]$. Migration (category 4$)$ is rather frequently (12 papers) mentioned as a response option as well, either seasonally or for other shorter periods of time, such as return migration as well as permanently [40]. Violent behavior and social tensions (category 5) were discussed as the results of water shortage in two papers only [22,41]. Many studies $(n=18)$ found responses in several categories, which shows the variation in possible human responses related to reduced water availability, and highlights that people do not always choose a single response but make use of several options, combining short-term coping strategies with longer-term structural adjustments.

From the set of studies analyzed, no clear differences between the types of human responses considered in the different types of methods can be found (see Table 5). However, the methods do differ in the way human responses are considered. Studies using a systems dynamics approach focus, logically, at the system level, and do not consider human behavior explicitly, but studies using agent-based models do. The questions that studies, using system dynamics or agent-based models, seek to answer differ. Whereas agentbased models focus on understanding the various factors, including behavior, influencing decisions of actors, system dynamics models focus more frequently on understanding how the (water) system would be impacted because of certain responses. Although agent-based models could also be used to assess the wider system level impacts, and system dynamics models could also integrate knowledge on human behavior in system-level models, this may not often be done.

\subsection{Theories and Approaches to Conceptualizing Human Responses to Changes in Water Availability}

A variety of approaches were used to conceptualize human responses, which are summarized in Table 6 . We found that 24 of the studies analyzed used a deductive approach, which Locke [42] defined as "moving from the general to the specific." This implies that the research starts with a hypothesis based on existing theories or conceptual frameworks. Seventeen of the 24 studies used a distinctive underlying theory, of which almost half of the studies strictly followed the chosen theory throughout the study [32]. The rest of the studies loosely referred to a theory, using it mainly as inspiration for their conceptual framework or model [43]. In the analyzed studies, we identify three different types of theories for the conceptualization of human responses, including (1) economicallybased utility maximization theories, (2) behavioral theories from the field of sociology, psychology and migration studies, and (3) theories based on vulnerability and resilience concepts. 
Table 4. Human response types addressed.

\begin{tabular}{|c|c|c|c|c|c|}
\hline Study & $\begin{array}{c}\text { Short-Term } \\
\text { Coping Strategies }\end{array}$ & $\begin{array}{c}\text { Income } \\
\text { Diversification }\end{array}$ & $\begin{array}{l}\text { Agricultural } \\
\text { Adaptation }\end{array}$ & Migration & Conflict \\
\hline Alam, 2015 & & & 1 & & \\
\hline Ashraf et al., 2014 & 1 & 1 & 1 & 1 & \\
\hline Asseng et al., 2010 & & & 1 & & \\
\hline Bai et al., 2019 & 1 & & & & \\
\hline Berger, et al., 2017 & 1 & & & 1 & \\
\hline Berhanu and Beyene, 2015 & & 1 & 1 & & \\
\hline Bommel et al., 2014 & & & 1 & & \\
\hline Boone et al., 2011 & 1 & 1 & & 1 & \\
\hline Bradley and Grainger, 2004 & 1 & 1 & 1 & 1 & \\
\hline Butler and Gates, 2012 & & 1 & & & 1 \\
\hline Carter and Janzen, 2017 & 1 & & & & \\
\hline Clark and Crabtree, 2015 & 1 & & & 1 & \\
\hline Collman et al., 2016 & 1 & & 1 & 1 & \\
\hline Desta and Coppock, 2004 & & 1 & & & \\
\hline Dieguez Cameroni et al., 2014 & & & 1 & & \\
\hline Entwisle et al., 2008 & 1 & & & 1 & \\
\hline Esquivel-Hernández et al., 2018 & & & & & 1 \\
\hline Fagariba et al., 2018 & & 1 & 1 & & \\
\hline Gies et al., 2014 & & & 1 & 1 & \\
\hline Giuliani et al., 2016 & & & 1 & & \\
\hline Gohari et al., 2017 & & & 1 & & \\
\hline Gori Maia et al., 2018 & & & 1 & & \\
\hline Grosskopf et al., 2015 & & & 1 & & \\
\hline Hailegiorgis et al., 2018 & & & 1 & 1 & \\
\hline Hassani-Mahmooei and Parris, 2012 & & & & 1 & \\
\hline Kansiime and Mastenbroek, 2016 & & & 1 & & \\
\hline Khanian et al., 2019 & & & & 1 & \\
\hline Kotir et al., 2016 & & & 1 & 1 & \\
\hline Krömker et al., 2008 & 1 & & 1 & & \\
\hline Lawson and Kasirye, 2013 & 1 & & & & \\
\hline Martin et al., 2016 & & 1 & 1 & & \\
\hline Miller et al., 2014 & & & 1 & & \\
\hline Okpara et al., 2016 & 1 & 1 & 1 & & \\
\hline Pérez et al., 2016 & & & 1 & & \\
\hline Pope and Gimblett, 2015 & 1 & 1 & 1 & & \\
\hline Ryu et al., 2012 & & & 1 & & \\
\hline Twongyirwe et al., 2019 & 1 & & 1 & & \\
\hline Warner et al., 2015 & & & 1 & & \\
\hline Yazdanpanah et al., 2014 & & & 1 & & \\
\hline Total & 16 & 10 & 27 & 12 & 2 \\
\hline
\end{tabular}

Table 5. Human responses addressed in studies using different types of quantification methods.

\begin{tabular}{cccccc}
\hline Quantification Method & $\begin{array}{c}\text { Short-Term } \\
\text { Coping Strategies }\end{array}$ & $\begin{array}{c}\text { Income } \\
\text { Diversification }\end{array}$ & $\begin{array}{c}\text { Agricultural } \\
\text { Adaptation }\end{array}$ & Migration & Conflict \\
\hline Statistical methods & 5 & 5 & 11 & 2 & 1 \\
Agent-based models & 6 & 3 & 9 & 6 & 0 \\
System dynamics & 1 & 0 & 6 & 0 & 1 \\
Optimization & 1 & 1 & 1 & 0 & 1 \\
Other & 1 & 1 & 27 & 12 \\
Total & 14 & 10 & & \\
\hline
\end{tabular}


Table 6. Approaches, theories, and concepts used.

\begin{tabular}{|c|c|c|}
\hline Study & Approach & Specific Theory or Concepts Used \\
\hline Alam, 2015 & Deductive & Utility maximization \\
\hline Ashraf et al., 2014 & Inductive & None/unclear \\
\hline Asseng et al., 2010 & Deductive & Utility maximization \\
\hline Bai et al., 2019 & Inductive & None/unclear \\
\hline Berger, et al., 2017 & Deductive & Utility maximization \\
\hline Berhanu and Beyene, 2015 & Deductive & Utility maximization \\
\hline Bommel et al., 2014 & Inductive & Participatory methods \\
\hline Boone et al., 2011 & Deductive & Insights from previous studies \\
\hline Bradley and Grainger, 2004 & Deductive & Resilience theory \\
\hline Butler and Gates, 2012 & Deductive & Utility maximization \\
\hline Carter and Janzen, 2017 & Deductive & Utility maximization \\
\hline Clark and Crabtree, 2015 & Deductive & Insights from previous studies \\
\hline Collman et al., 2016 & Deductive & Behavioral theory: dread-threat theory \\
\hline Desta and Coppock, 2004 & Deductive & Insights from previous studies \\
\hline Dieguez Cameroni et al., 2014 & Inductive & Participatory methods \\
\hline Entwisle et al., 2008 & Deductive & Insights from previous studies \\
\hline Esquivel-Hernández et al., 2018 & Inductive & None/unclear \\
\hline Fagariba et al., 2018 & Inductive & None/unclear \\
\hline Gies et al., 2014 & Inductive & None/unclear \\
\hline Giuliani et al., 2016 & Deductive & Utility maximization \\
\hline Gohari et al., 2017 & Deductive & Utility maximization \\
\hline Gori Maia et al., 2018 & Inductive & None/unclear \\
\hline Grosskopf et al., 2015 & Inductive & Participatory methods \\
\hline Hailegiorgis et al., 2018 & Deductive & Behavioral theory: protection motivation theory \\
\hline Hassani-Mahmooei and Parris, 2012 & Deductive & Behavioral theory: push-pull theory \\
\hline Kansiime and Mastenbroek, 2016 & Deductive & Resilience theory \\
\hline Khanian et al., 2019 & Deductive & Resilience theory \\
\hline Kotir et al., 2016 & Inductive & Participatory methods \\
\hline Krömker et al., 2008 & Deductive & Behavioral theory: protection motivation theory \\
\hline Lawson and Kasirye, 2013 & Deductive & Based on insights from available literature \\
\hline Martin et al., 2016 & Deductive & Resilience theory \\
\hline Miller et al., 2014 & Inductive & Participatory methods \\
\hline Okpara et al., 2016 & Inductive & None/unclear \\
\hline Pérez et al., 2016 & Deductive & Insights from previous studies \\
\hline Pope and Gimblett, 2015 & Inductive & Participatory methods \\
\hline Ryu et al., 2012 & Inductive & Participatory methods \\
\hline Twongyirwe et al., 2019 & Inductive & None/unclear \\
\hline Warner et al., 2015 & Deductive & Insights from previous studies \\
\hline Yazdanpanah et al., 2014 & Deductive & Behavioral theory: theory of planned behavior \\
\hline
\end{tabular}

The most frequently applied $(n=8)$ theory is utility maximization, which originates from welfare economics, assuming that people make rational decisions that optimize their welfare. This theory accounts for the comparison of different individual responses. For example, Berhanu et al. [32] developed a model for the analysis of pastoralist responses to long-term climatic variability based on pastoral household utility maximization, whereas the system dynamics model of Gohari et al. [25] used income-maximization as the main determinant for agricultural land use decisions.

Individual behavioral theories developed in sociology or psychology were used in five of the analyzed studies. This ranges from commonly used theories, such as the theory of planned behavior, to theories predominantly applied to the field of migration. We found that only Hailegiorgis et al. [44], Krömker et al. [43], and Yazdanpanah et al. [45] used commonly known behavioral theories in their studies, respectively, the protection motivation theory and the theory of planned behavior. The protection motivation theory states that peoples' decisions to protect themselves is based on the (1) perceived severity of a threatening event, (2) the perceived probability of the occurrence, (3) the expectancy that the recommended behavior is effective and (4) the ability of the person to execute the 
recommended courses of action successfully [46]. Hailegiorgis et al. [44] used this theory as part of a framework that describes the socio-cognitive adaptive behavior of households, which helps to explain the subjective adaptive capacity of individuals to climate change. Krömker et al. [43] indirectly used the theory by applying a psychological action model which is based on the protection motivation theory. The theory of planned behavior started as the theory of reasoned action to predict an individual's intention to engage in a behavior, intending to explain the majority of individuals' behavior [47]. It links beliefs to behavior based on the (1) attitude of an individual towards a behavior, (2) the subjective norm based on the individual's social network and other social norms, and (3) the perceived behavioral control, including capacity and autonomy in the choice to adapt. Yazdanpanah et al. (2014) built on the theory of planned behavior and expanded this with moral norms to analyze water conservation adaptation responses. Both these theories allow for the evaluation of a range of possible human responses.

The migration-focused push-pull theories and dread-threat theory use similar behavioral insights, such as the individual's motivation to change and expectancy of the behavior, however, they are mainly developed to explain migration. Lee's [48] push-pull theory conceptualized the motivation of an individual to migrate by factors associated with the area of origin, factors associated with the area of destination, intervening obstacles and personal factors. The push-pull theory is still one of the most used theories to explain humans' decision to migrate. Hassani-Mahmooei and Parris [49] used this migration decision theory to model the migration dynamics of inhabitants of Bangladesh. Dread-threat theory originates from psychology and is related to the Intergovernmental Panel on Climate Change's risk framework. It explores how the local perception of threat affects the decision-making about remaining in place, migrating or both. The perceived uncertainty of the threat is combined with the perceived impact of the threat; for example, an unpleasant death for future generations at risk. Collman et al. [50] further developed the theory based on anthropological and journalistic accounts and translated this qualitative theory to a partly quantitative model to evaluate the attractiveness of threat response strategies. The two theories from the field of migration focus on the decision whether to migrate. Alternative human responses are not considered.

Four other papers used resilience or vulnerability theory as part of a socio-ecological framework to describe human responses. Unlike the utility maximization and individual behavioral theories, these are not well-defined theories to simulate responses. Typically, these papers relate components related to resilience, such as exposure, vulnerability, and adaptive capacity of individuals to human responses. For example, Martin et al. [51] developed a framework to provide insights into the vulnerability of pastoral households in relation to droughts, which was based on, amongst others, vulnerability and livelihood security concepts, whereas Kansiime [52] employed a framework that combined social and ecological approaches to analyze resilient behavior. In addition, Bradley and Grainger [23] assessed resilient behavior to develop a social resilience model to describe the switch from performance strategies to survival strategies. Khanian et al. [40] developed a conceptual model based on the relation between mechanisms of place attachment and adaptive capacity on migration decisions. Most of these papers do not use a single theory but combine theories with information from literature or their own insights.

The remaining seven of the 24 deductive studies did not explicitly apply a human response theory but used either qualitative or quantitative information from previous studies as a starting point for a hypothesis of human responses. The information could be part of an existing model, as demonstrated by Boone et al. [29], who used the household model DECUMA to simulate decision-making or based on literature as shown by Desta and Coppock [33] who used historic behavior of the Maasai to explore behavior of the Borana society.

As an alternative to a purely deductive approach, participatory methods were used to develop a conceptual framework or model through inductive methods, in which rules and cause-effect relations are derived from observations. We found seven studies that 
used participatory methods. A method was defined as participatory when there was active communication with a stakeholder group, ranging from focus group discussions and participatory modeling to virtual experiments. The execution of only a survey is not considered a participatory approach. For example, Bommel et al. [53] demonstrated an approach in which an agent-based model was designed together with livestock farmers through several participatory workshops. In addition, Dieguez et al. [54] used local knowledge as the basis for their agent-based model using a series of workshops to define decision-making strategies, which became a decisional sub-model in the Decision-Support System SequiaBasalto. Most participatory (design) methods use local data and information to develop a model that simulates decision-making in the same local or regional context. This relates to an indicative approach in which generic lessons can be drawn based on local data without using an existing theory.

Aside from studies that used a human response theory or inductive participatory approach, eights studies were categorized as not using a specifically defined human response approach or theory. These are primarily econometric or statistical studies using results of questionnaires or census data to derive relations between human responses and other variables. These studies do not specify a human response hypothesis based on theories or literature but carry out an analysis to answer the main research questions based on available (census) datasets or questionnaire results, sometimes implicitly informed by conceptual models and cause-effect relations from previous literature. For example, Ashraf [28] evaluated farmers' coping and adaptation behavior towards drought through a survey, without mentioning a specific hypothesis. In addition, Bai et al. [26] used questionnaires, consisting of household census and adaptation measures, to define the most adopted adaptation measures and to relate adaptation to technical efficiency of livestock production. Esquivel-Hernández et al. [41] conducted a spatial distribution and temporal analysis of water conflicts, making the link between conflicts and hydro-meteorological events. These studies can be considered as inductive, as these studies were not designed to test an existing theory, but to find correlations and patterns in behavior.

\subsection{Policy Applications}

We assessed the articles for the connection they made with possibilities for new policies or interventions to facilitate or guide the autonomous actions, and to improve the coping capacity and structural adaptation to temporary or structural changes in water availability. Our small sample does not allow us to draw firm conclusions, but we did notice that the way policies are addressed varies across the studies that apply different types of quantification methods (see Table 7).

Table 7. Connections of research findings to policy recommendations.

\begin{tabular}{cccc}
\hline Quantification Method & Policy Analysis & Policy Suggestion & No Link with Policies \\
\hline Statistical methods & 0 & 11 & 5 \\
System dynamics & 5 & 0 & 1 \\
Agent-based models & 2 & 1 & 11 \\
Optimization & 1 & 0 & 1 \\
Other & 0 & 0 & 1 \\
Total & 8 & 12 & 19 \\
\hline
\end{tabular}

Approximately half $(n=20)$ of the studies relate their findings on human responses to policy. Twelve of these use new insights in the functioning of the system or the identification of major determinants to suggest directions for possible policies. This was found especially among studies applying statistics analysis and correlation methods. The other eight studies give more comprehensive policy recommendations, including an analysis of the impact of alternative policy options. In particular, the system dynamics are set up in a way that policy options can easily be compared, which provides direct policy advice. As these studies mainly focus on policy, behavioral dynamics are often simplified. For example, 
Gohari et al. [25] analyzed the impact of agriculture adaptation strategies with a system dynamics model, including water demand and water use in the socio-economic sub-system of their system dynamics model, without further detailing human behavior. There are few examples of models that both modeled human behavior and analyzed the impact of policy options. Berger et al. [27] is one of these examples, simulating individual farming decisions in their agent-based model, and analyzing different policy interventions, such as fertilizer subsidy and providing credit. This model used utility maximization theory as a basis, simplifying human behavior to optimizing of income. The majority of the publications analyzed $(n=19)$ focus on identifying major factors explaining a certain type of behavior, without using the results to suggest ways to actively influence the systems and the outcomes; this is often the case in studies applying agent-based modeling. Some studies do indicate a possibility to apply the model to explore policy options, as a potential next step.

\section{Discussion}

The aim of the study presented here is to identify conceptual models and theories that help quantify human responses to water-related events and water scarcity, in particular. We are looking for practical guidance on how to assess impacts on people beyond firstorder impacts. This is important to identify possible further impacts such as autonomous adaptation, to be aware of unintended impacts such as impoverishment, displacement, or social tensions, and because certain responses could have feedbacks on the water system itself. Without giving any value judgment on desired or undesired consequences, we argue that it is important to understand the consequences of man-made or natural changes to water systems, in order to develop effective and adequate policies for drought relief, water management or climate adaptation.

Previous reviews discussed the selection of the most suitable methods for water resources modeling $[55,56]$ or public participation [57] and identified gaps and next steps in relation to modeling of specific environment-society linkages [58,59]. With regard to integrating human behavior in water systems analysis, this paper adds two aspects to existing reviews: (1) a broad view on human responses to drought and water shortage, whereas other studies focus either on feedbacks of human behavior on water systems [18], or on specific responses such as migration [59]; and (2) a systematic analysis of the approaches to address human behavior in relation to drought and water shortage. Insights in the approaches used can facilitate the integration of human behavior in water-related policy analysis and planning.

Therefore, we were specifically interested in frameworks, theories and conceptual models that can help to gain insights in possible responses and the factors determining human behavior in response to changes in water availability. From our analysis, we found that less than half of the studies we analyzed made use of, or referred to, behavioral theory from either the field of economics, psychology, anthropology or sociology. The relatively small number of articles that refer to such a theory is in line with the findings of Davis et al. [60], who observed that less than one-fourth of the studies about behavior actually use behavioral theory, and that when it is used, it is often relatively loosely referred to. Furthermore, we observed that although many studies have an interdisciplinary approach, typically one discipline is most developed. For example, Gies et al. [24] used a comprehensive hydrological model, whereas the socio-economic and behavioral aspects receive less attention. The opposite is observed in Collman et al. [50] who used a thorough analysis of human responses and paid less attention to the physical system. This could be explained by the background of the researchers and the need for demarcation of research. However, for a policy study, a balance between the different disciplines could be beneficial.

From the behavioral theories referred to in the analyzed studies, we can derive key elements that are generally considered important when quantifying human responses to changes in water availability: 
1. Aspirations or objectives. It is important to identify what it is that individuals or groups aim to achieve. Maximization of profit is in the analyzed studies the most frequently used method to guide human behavior. Bounded rationality, the idea that rationality is limited when individuals make decisions, is becoming widely accepted as an alternative to utility maximization. Incorporating aspects of bounded rationality in a human response model requires the introduction of sufficient stochastic processes and a wide range of aspects that influence decisions, such as mental well-being, health, and a feeling of security. We saw a limited number of studies that entirely integrated bounded rationality in their model. For example, Yazdanpanah et al. [45] included many factors related to bounded rationality, such as the impact of perceived risk on the intention to conserve water, but they did not build a model. Incorporating clear objectives in the model likely makes it easier to analyze the results. However, setting objectives is not entirely in line with the idea of bounded rationality.

2. Response options. We observed that some studies consider a wide ranges of response options, while others focus on one or a few. Our observation is that statistical studies, aiming to explain what factors determine the choice for a certain option have a broader perspective, while studies quantifying response behavior consider a limited, specific set of options such as income diversification, improving water infrastructures or migration. Further, qualitative studies, which we did not include in our analysis, often provide a wealth of information on the many different ways in which people cope with changes in water availability, and drought specifically (e.g., [61]).

3. Factors influencing the attractiveness of responses options. All studies identify factors that influence decisions on which (a combination of) responses to pursue, either based on existing conceptual models describing human responses or based on explanatory factors mentioned in literature. Factors can be further divided into three types, all considering characteristics on an individual level (e.g., age, skills, risk averseness), the household level (e.g., ownership of land), and societal level (e.g., demography, economy, institutions):

a. Factors making current behavior unattractive. This is a key element in many of the theories (e.g., push-pull, dread-threat).

b. Factors making alternatives attractive. This is a key element in many theories which optimize behavior to achieve a certain outcome. It is also an explicit element of the 'pull' factor.

c. Factors inhibiting change. There can be reasons why a different type of behavior is theoretically more attractive, but people may be reluctant to act upon such an opportunity.

4. Decision rules determining the choice to move from a certain behavior to a different type of behavior. For example, a change is only made when a certain threshold is exceeded. Bradley and Grainger [23] describe this as performance threshold, to switch between survival and performance strategies, whereas Martin et al. [51] describe this as resilience: a certain impact can be withstood during a certain time, depending on buffers people have. Where studies differ is to what extent decision-making rules are made explicit, and what these decision rules entail. For example, studies using statistical analysis (e.g., multinominal regression) are interested in understanding which factors explain certain responses best, but do not normally seek to explain how exactly the decision-making behavior works. Results from such statistical studies could feed decision rules.

The purpose of this paper was to understand how human responses were quantified in studies on water availability and drought. We are aware that other fields may have developed theories on human behavior that could be adopted for water management purposes. For example, Davis et al. [60] identified in their scoping study 82 theories of behavior and behavioral change from the fields of psychology, sociology, anthropology and economics, of which the most frequently applied are the transtheoretical model of change, the theory of planned behavior and the social cognitive theory. The theory of 
planned behavior was also found in the studies analyzed here. It would be worthwhile to also explore the applicability on water issues and additional insights from other theories in future work. The relatively minor use of behavioral theories in the analyzed studies might be explained by the researchers that work on these studies. Most researchers have a background in climate change, hydrology, water management or policy studies and are potentially less familiar with psychology and sociology disciplines, which is the main source of behavioral theories.

What does this mean for better integrating human responses in planning studies? As we introduced earlier in this work, planning studies often consider large spatial scales, such as river basins or countries, consider various sectors, and need to be finalized within certain time and resource constraints. In practice, this could mean that it will not be possible to develop a detailed agent-based model and run it for various scenarios and alternative water management strategies. Based on our analysis, we identified that qualitative and statistical studies explaining historic behavior often consider a wide range of possible responses. These could offer a starting point for a planning study, to identify what would be the possible responses for different stakeholder groups. It can subsequently be decided, for example, through a stakeholder consultation, which of these options are likely and require further study and quantification. Therefore, we suggest the following steps:

1. Identify the areas most at risk from future development or water resources management measures in the study area.

2. Identify the different societal groups that live in or have their livelihoods based on these areas, for example, through combining maps of occurrence of water-related hazards with administrative maps.

3. Start with a broad assessment on the possible responses.

4. Select a set of options to quantify in more detail through either system level models in which behavior is aggregated, or agent-based models to allow individual level analysis.

5. Select a single or set of theories and related conceptualization, that support the identification of objectives/aspirations, decision-influencing factors, and response rules.

6. Identify data collection options that are both feasible and do justice to the context and complexities, including previous research findings in similar areas/situations, key information interviews or field surveys.

7. Integrate the quantitative analysis in the water system analysis to obtain insights in possible social consequences and effectiveness of water management actions.

8. Identify and assess alternative water management actions or complementary policies, such as providing assistance to cope with short-term water shortage or to support people to structurally adjust their livelihood strategies.

\section{Conclusions}

To better understand the consequences of changes in water resources systems, either natural or man-made, it is important to understand how different groups of people would respond to a change in water availability. Responses could result in a feedback on the water system, for example through using more water, to the adoption or refusal of proposed new practices, or to further impoverishment, protests, or migration away from the area. To design effective policies, it is important to understand what factors and what levels of change in these factors could trigger specific responses. The purpose of this paper was to give an overview of the different ways through which human responses to changes in water availability were conceptualized and quantified.

We found that even in our limited sample of 39 studies that quantify human responses in relation to water scarcity and drought, many different approaches are used. Only a limited number of studies is based on behavioral theories. Although the specific research questions the studies seek to answer differ, with implication for the methods used, we think the quantification of human responses could benefit from combining concepts out of various theories, at least in the early stages of research projects and planning studies: 
(1) to consider a wide set of objectives or aspirations of people: profit maximization cannot explain everything, (2) to consider the (perceived) attractiveness of both current and alternative strategies, and (3) to consider how people use these perceptions to make decisions on how to best achieve their objectives. Then, it may be possible, or necessary given time, resource, or data constraints, to make a choice regarding the objectives, response options, and decision rules to model quantitatively, to ensure that human responses are integrated in the development of water management plans.

Author Contributions: Conceptualization, K.S.M., F.S. and M.B.; formal analysis, K.S.M., F.S. and M.B.; writing-original draft preparation, K.S.M. and F.S.; review and editing, M.B. All authors have read and agreed to the published version of the manuscript.

Funding: This research did not receive external funding.

Institutional Review Board Statement: Not applicable.

Informed Consent Statement: Not applicable.

Data Availability Statement: Not applicable.

Acknowledgments: We thank three anonymous reviewers and the Special Issue editor for their constructive comments that helped improve this paper.

Conflicts of Interest: The authors declare no conflict of interest.

\section{References}

1. Hallegatte, S.; Vogt-Schilb, A.; Bangalore, M.; Rozenberg, J. Unbreakable: Building the Resilience of the Poor in the Face of Natural Disasters; World Bank Publications: Washington, DC, USA, 2016.

2. Rigaud, K.K.; de Sherbinin, A.; Jones, B.; Bergmann, J.; Clement, V.; Ober, K.; Schewe, J.; Adamo, S.; McCusker, B.; Heuser, S.; et al. $>$ Groundswell. Preparing for Internal Climate Displacement; World Bank: Washington DC, USA, 2018.

3. Kelley, C.P.; Mohtadi, S.; Cane, M.A.; Seager, R.; Kushnir, Y. Climate change in the Fertile Crescent and implications of the recent Syrian drought. Proc. Natl. Acad. Sci. USA 2015, 112, 3241-3246. [CrossRef]

4. Phi, H.L.; Hermans, L.M.; Douven, W.J.A.M.; Van Halsema, G.E.; Khan, M.F. A framework to assess plan implementation maturity with an application to flood management in Vietnam. Water Int. 2015, 40, 984-1003. [CrossRef]

5. Boas, I.; Farbotko, C.; Adams, H.; Sterly, H.; Bush, S.; van der Geest, K.; Wiegel, H.; Ashraf, H.; Baldwin, A.; Bettini, G.; et al. Climate migration myths. Nat. Clim. Chang. 2019, 9, 901-903. [CrossRef]

6. Wiegel, H.; Warner, J.; Boas, I.; Lamers, M. Safe from what? Understanding environmental non-migration in Chilean Patagonia through ontological security and risk perceptions. Reg. Environ. Chang. 2021, 21, 1-13. [CrossRef]

7. Foresight. Final Project Report-Foresight: Migration and Global Environmental Change; Government Office for Science: London, UK, 2011.

8. World Bank. Pathways for Peace: Inclusive Approaches to Preventing Violent Conflict; The World Bank: Washington, DC, USA, 2018.

9. Raineri, L. If Victims Become Perpetrators: Factors Contributing to Vulnerability and Resilience to Violent Extremism in the Central Sahel; International Alert: London, UK, 2018.

10. Di Baldassarre, G.; Sivapalan, M.; Rusca, M.; Cudennec, C.; Garcia, M.; Kreibich, H.; Konar, M.; Mondino, E.; Mård, J.; Pande, S.; et al. Sociohydrology: Scientific challenges in addressing the sustainable development goals. Water Resour. Res. 2019, 55, 6327-6355. [CrossRef]

11. Beckage, B.; Gross, L.J.; Lacasse, K.; Carr, E.; Metcalf, S.S.; Winter, J.M.; Howe, P.D.; Fefferman, N.; Franck, T.; Zia, A.; et al. Linking models of human behaviour and climate alters projected climate change. Nat. Clim. Chang. 2018, 8, 79-84. [CrossRef]

12. Gowdy, J.M. Organization. Behavioral economics and climate change policy. J. Econ. Behav. Organ. 2008, 68, 632-644. [CrossRef]

13. Loucks, D.P.; Van Beek, E. Water Resource Systems Planning and Management: An. Introduction to Methods, Models, and Applications; Springer: Berlin/Heidelberg, Germany, 2017.

14. Meijer, K.S.; Van Beek, E. A framework for the quantification of the importance of environmental flows for human well-being. Soc. Nat. Resour. 2011, 24, 1252-1269. [CrossRef]

15. GWP. Integrated Water Resoruces Mangement; Global Water Partnership: Stockholm, Sweden, 2000.

16. Jeffrey, P. The human dimensions of IWRM: Interfaces between knowledges and ambitions. In Integrated Urban Water Resources Management; Springer: Berlin/Heidelberg, Germany, 2006; pp. 11-18.

17. Sivapalan, M.; Savenije, H.H.; Blöschl, G. Socio-hydrology: A new science of people and water. Hydrol. Process. 2012, 26, 1270-1276. [CrossRef]

18. Konar, M.; Garcia, M.; Sanderson, M.R.; David, J.Y.; Sivapalan, M. Expanding the scope and foundation of sociohydrology as the science of coupled human-water systems. Water Resour. Res. 2019, 55, 874-887. [CrossRef] 
19. Gunda, T.; Turner, B.L.; Tidwell, V.C. The influential role of sociocultural feedbacks on community-managed irrigation system behaviors during times of water stress. Water Resour. Res. 2018, 54, 2697-2714. [CrossRef]

20. Pande, S.; Savenije, H.H. A sociohydrological model for smallholder farmers in Maharashtra, India. Water Resour. Res. 2016, 52, 1923-1947. [CrossRef]

21. Elsevier. Scopus. 2019. Available online: www.scopus.com (accessed on 28 May 2019).

22. Butler, C.K.; Gates, S. African range wars: Climate, conflict, and property rights. J. Peace Res. 2012, 49, 23-34. [CrossRef]

23. Bradley, D.; Grainger, A. Social resilience as a controlling influence on desertification in Senegal. Land Degrad. Dev. 2004, 15, 451-470. [CrossRef]

24. Gies, L.; Agusdinata, D.B.; Merwade, V. Drought adaptation policy development and assessment in East Africa using hydrologic and system dynamics modeling. Nat. Hazards 2014, 74, 789-813. [CrossRef]

25. Gohari, A.; Mirchi, A.; Madani, K. System Dynamics Evaluation of Climate Change Adaptation Strategies for Water Resources Management in Central Iran. Water Resour. Manag. 2017, 31, 1413-1434. [CrossRef]

26. Bai, Y.; Deng, X.; Zhang, Y.; Wang, C.; Liu, Y. Does climate adaptation of vulnerable households to extreme events benefit livestock production? J. Clean. Prod. 2019, 210, 358-365. [CrossRef]

27. Berger, T.; Troost, C.; Wossen, T.; Latynskiy, E.; Tesfaye, K.; Gbegbelegbe, S. Can smallholder farmers adapt to climate variability, and how effective are policy interventions? Agent-based simulation results for Ethiopia. Agric. Econ. 2017, 48, 693-706. [CrossRef]

28. Ashraf, M.; Routray, J.K.; Saeed, M. Determinants of farmers' choice of coping and adaptation measures to the drought hazard in northwest Balochistan, Pakistan. Nat. Hazards 2014, 73, 1451-1473. [CrossRef]

29. Boone, R.B.; Galvin, K.A.; BurnSilver, S.B.; Thornton, P.K.; Ojima, D.S.; Jawson, J.R. Using coupled simulation models to link pastoral decision making and ecosystem services. Ecol. Soc. 2011, 16. [CrossRef]

30. Entwisle, B.; Malanson, G.; Rindfuss, R.R.; Walsh, S.J. An agent-based model of household dynamics and land use change. J. Land Use Sci. 2008, 3, 73-93. [CrossRef]

31. Twongyirwe, R.; Mfitumukiza, D.; Barasa, B.; Naggayi, B.R.; Odongo, H.; Nyakato, V.; Mutoni, G. Perceived effects of drought on household food security in South-western Uganda: Coping responses and determinants. Weather Clim. Extrem. 2019, $24,100201$. [CrossRef]

32. Berhanu, W.; Beyene, F. Climate variability and household adaptation strategies in southern Ethiopia. Sustainability 2015, 7, 6353-6375. [CrossRef]

33. Desta, S.; Coppock, D.L. Pastoralism under pressure: Tracking system change in Southern Ethiopia. Hum. Ecol. 2004, 32, 465-486. [CrossRef]

34. Okpara, U.T.; Stringer, L.C.; Dougill, A.J. Lake drying and livelihood dynamics in Lake Chad: Unravelling the mechanisms, contexts and responses. Ambio 2016, 45, 781-795. [CrossRef]

35. Gori Maia, A.; Cesano, D.; Miyamoto, B.C.B.; Eusebio, G.S.; Silva, P.A.O. Climate change and farm-level adaptation: The Brazilian Sertão. Int. J. Clim. Chang. Strateg. Manag. 2018, 10, 729-751. [CrossRef]

36. Becerra, S.; Saqalli, M.; Gangneron, F.; Dia, A.H. Everyday vulnerabilities and "social dispositions" in the Malian Sahel, an indication for evaluating future adaptability to water crises? Reg. Environ. Chang. 2016, 16, 1253-1265. [CrossRef]

37. Grosskopf, H.M.; Tourrand, J.F.; Bartaburu, D.; Dieguez, F.; Bommel, P.; Corral, J.; Montes, E.; Pereira, M.; Duarte, E.; Hegedus, P. Use of simulations to enhance knowledge integration and livestock producers' adaptation to variability in the climate in northern Uruguay. Rangel. J. 2015, 37, 425-432. [CrossRef]

38. Fagariba, C.J.; Song, S.; Baoro, S.K.G.S. Climate change in Upper East Region of Ghana; Challenges existing in farming practices and new mitigation policies. Open Agric. 2018, 3, 524-536. [CrossRef]

39. Alam, K. Farmers' adaptation to water scarcity in drought-prone environments: A case study of Rajshahi District, Bangladesh. Agric. Water Manag. 2015, 148, 196-206. [CrossRef]

40. Khanian, M.; Serpoush, B.; Gheitarani, N. Balance between place attachment and migration based on subjective adaptive capacity in response to climate change: The case of Famenin County in Western Iran. Clim. Dev. 2019, 11, 69-82. [CrossRef]

41. Esquivel-Hernández, G.; Sánchez-Murillo, R.; Birkel, C.; Boll, J. Climate and Water Conflicts Coevolution from Tropical Development and Hydro-Climatic Perspectives: A Case Study of Costa Rica. J. Am. Water Resour. Assoc. 2018, 54, 451-470. [CrossRef]

42. Locke, E.A. The case for inductive theory building. J. Manag. 2007, 33, 867-890. [CrossRef]

43. Krömker, D.; Eierdanz, F.; Stolberg, A. Who is susceptible and why? An agent-based approach to assessing vulnerability to drought. Reg. Environ. Chang. 2008, 8, 173-185. [CrossRef]

44. Hailegiorgis, A.; Crooks, A.; Cioffi-Revilla, C. An agent-based model of rural households' adaptation to climate change. JASSS 2018, 21. [CrossRef]

45. Yazdanpanah, M.; Hayati, D.; Hochrainer-Stigler, S.; Zamani, G.H. Understanding farmers' intention and behavior regarding water conservation in the Middle-East and North Africa: A case study in Iran. J. Environ. Manag. 2014, 135, 63-72. [CrossRef]

46. Rogers, R.W. A protection motivation theory of fear appeals and attitude change1. J. Psychol. 1975, 91, 93-114. [CrossRef]

47. Ajzen, I. From intentions to actions: A theory of planned behavior. In Action Control; Springer: Berlin/Heidelberg, Germany, 1985; pp. 11-39.

48. Lee, E.S. A theory of migration. Demography 1966, 3, 47-57. [CrossRef] 
49. Hassani-Mahmooei, B.; Parris, B.W. Climate change and internal migration patterns in Bangladesh: An agent-based model. Environ. Dev. Econ. 2012, 17, 763-780. [CrossRef]

50. Collman, J.; Blake, J.; Bridgeland, D.; Kinne, L.; Yossinger, N.S.; Dillon, R.; Martin, S.; Zou, K. Measuring the potential for mass displacement in menacing contexts. J. Refug. Stud. 2016, 29, 273-294. [CrossRef]

51. Martin, R.; Linstädter, A.; Frank, K.; Müller, B. Livelihood security in face of drought-Assessing the vulnerability of pastoral households. Environ. Model. Softw. 2016, 75, 414-423. [CrossRef]

52. Kansiime, M.K.; Mastenbroek, A. Enhancing resilience of farmer seed system to climate-induced stresses: Insights from a case study in West Nile region, Uganda. J. Rural Stud. 2016, 47, 220-230. [CrossRef]

53. Bommel, P.; Dieguez, F.; Bartaburu, D.; Duarte, E.; Montes, E.; Machín, M.P.; Corral, J.; Pereira de Lucena, C.J.; Grosskopf, H.M. A further step towards participatory modelling. fostering stakeholder involvement in designing models by using executable UML. JASSS 2014, 17. [CrossRef]

54. Dieguez Cameroni, F.J.; Terra, R.; Tabarez, S.; Bommel, P.; Corral, J.; Bartaburu, D.; Pereira, M.; Montes, E.; Duarte, E.; Morales Grosskopf, H. Virtual experiments using a participatory model to explore interactions between climatic variability and management decisions in extensive grazing systems in the basaltic region of Uruguay. Agric. Syst. 2014, 130, 89-104. [CrossRef]

55. De Almeida Castro, A.L.; Andrade, E.P.; de Alencar Costa, M.; de Lima Santos, T.; Ugaya, C.M.L.; de Figueirêdo, M.C.B. Applicability and relevance of water scarcity models at local management scales: Review of models and recommendations for Brazil. Environ. Impact Assess. Rev. 2018, 72, 126-136. [CrossRef]

56. Addor, N.; Melsen, L. Legacy, rather than adequacy, drives the selection of hydrological models. Water Resour. Res. 2019, 55, 378-390. [CrossRef]

57. Voinov, A.; Jenni, K.; Gray, S.; Kolagani, N.; Glynn, P.D.; Bommel, P.; Prell, C.; Zellner, M.; Paolisso, M.; Jordan, R.; et al. Tools and methods in participatory modeling: Selecting the right tool for the job. Environ. Model. Softw. 2018, 109, 232-255. [CrossRef]

58. Hedelin, B.; Gray, S.; Woehlke, S.; BenDor, T.; Singer, A.; Jordan, R.; Zellner, M.; Giabbanelli, P.; Glynn, P.; Jenni, K.J.E.M.; et al. What's left before participatory modeling can fully support real-world environmental planning processes: A case study review. Environ. Model. Softw. 2021, 143, 105073. [CrossRef]

59. Thober, J.; Schwarz, N.; Hermans, K.J.E. Agent-based modeling of environment-migration linkages. Ecol. Soc. $2018,23,41$.

60. Davis, R.; Campbell, R.; Hildon, Z.; Hobbs, L.; Michie, S. Theories of behaviour and behaviour change across the social and behavioural sciences: A scoping review. Health Psychol. Rev. 2015, 9, 323-344. [CrossRef]

61. Opiyo, F.; Wasonga, O.; Nyangito, M.; Schilling, J.; Munang, R. Drought Adaptation and Coping Strategies Among the Turkana Pastoralists of Northern Kenya. Int. J. Disaster Risk Sci. 2015, 6, 295-309. [CrossRef] 